\title{
Formaldehyde Exposure, Health Symptoms and Risk Assessment among Hospital Workers in Malaysia
}

\author{
Sharifah Mazrah Sayed Mohamed Zain* ${ }^{(0)}$, Wan Nurul Farah Wan Azmi, Yuvaneswary Veloo, \\ Rafiza Shaharudin
}

Environmental Health Research Centre, Institute for Medical Research, Ministry of Health Malaysia, Shah Alam, Malaysia

Email: *sharifah@imr.gov.my

How to cite this paper: Zain, S.M.S.M., Azmi, W.N.F.W., Veloo, Y. and Shaharudin, R. (2019) Formaldehyde Exposure, Health Symptoms and Risk Assessment among Hospital Workers in Malaysia. Journal of Environmental Protection, 10, 861-879.

https://doi.org/10.4236/jep.2019.106051

Received: April 19, 2019

Accepted: June 21, 2019

Published: June 24, 2019

Copyright $\odot 2019$ by author(s) and Scientific Research Publishing Inc. This work is licensed under the Creative Commons Attribution International License (CC BY 4.0).

http://creativecommons.org/licenses/by/4.0/

\begin{abstract}
Formaldehyde is a chemical commonly used in hospitals as a tissue preservative; histopathology laboratory personnel are therefore among the workers most heavily exposed to formaldehyde. This study measured the formaldehyde exposure through ambient and personal air sampling, assessed the symptoms of poor health as well as estimating the health risk among hospital workers. We conducted a comparative cross-sectional study of both histopathology laboratory (exposed) and administration (nonexposed) workers in four hospitals in the Klang Valley, Selangor, Malaysia. Ambient and personal exposure to formaldehyde was measured using the OSHA 52 and NIOSH 2541 methods, respectively. The 8-hr time-weighted-average formaldehyde concentration was higher in exposed areas $(0.25 \pm 0.11 \mathrm{ppm})$ than nonexposed areas $(0.08 \pm 0.02 \mathrm{ppm})$. Histopathology workers were exposed to between $140 \%$ and $480 \%$ higher concentrations of formaldehyde than administration workers. Personal exposure was highest during grossing tasks $(0.797 \pm$ $0.436 \mathrm{ppm})$. A total of $67 \%$ of the exposed workers exhibited the same ten health symptoms related to formaldehyde exposure, and $57 \%$ of the nonexposed workers reported similar symptoms at their current workplace. Notably, symptoms of eye irritation, headache, drowsiness, and chest tightness were significantly more prevalent $(\mathrm{p}<0.05$; chi square and Fisher's exact tests) among the exposed workers than the nonexposed workers. Among those with symptoms, $37 \%$ of the exposed workers, and $16 \%$ of the nonexposed workers believed that the symptoms were related to their current working environment. The noncancer effect of formaldehyde from air inhalation poses a potential risk of eye irritation among exposed workers. The cancer risk was not significant in both groups. Formaldehyde levels and symptoms of poor health were significantly higher among the exposed group. Ex-
\end{abstract}


posure and risk could be minimised by strengthening control measures to improve indoor air quality in the workplace.

\section{Keywords}

Healthcare Workers, Histopathology Laboratory, Health Risk Estimation, Occupational Exposure

\section{Introduction}

Formaldehyde is used widely in medical applications worldwide, including as a tissue preservative in pathology laboratories, as a sterilising agent, and as a disinfectant in operating rooms [1] [2]. It is considered an occupational indoor air pollutant [3] [4] [5] because it volatilizes easily and is emitted into the working environment. Healthcare workers in contact with formaldehyde in histopathology and anatomy laboratories are at greater risk than other individuals because they are exposed to higher amounts of formaldehyde on a daily basis, either through inhalation or direct contact with the skin [6]. Various studies have shown that acute and chronic exposure to formaldehyde through inhalation is associated with respiratory symptoms and irritation of the eyes, nose, and throat [7]-[13]. Other researchers have identified formaldehyde levels in hospital pathology laboratories exceeding the permissible exposure limit [4] [14] [15]. For example, Ghameskhani et al. [14] reported that staff in pathology laboratories were exposed to higher levels of formaldehyde than staff in surgery rooms, and endoscopy wards, and that more than $80 \%$ of those exposed reported eye irritations. One research study also reported that formaldehyde levels in air that exceed $0.1 \mathrm{ppm}$ can cause watery eyes, nausea, coughing, chest tightness, wheezing, skin rashes, allergic reactions, and burning sensations in the nose, throat, and eyes [16].

Since 1987, the United States Environmental Protection Agency (US EPA) [17] has classified formaldehyde as a probable human carcinogen under conditions of high or prolonged exposure. In June 2004, the International Agency for Research on Cancer reclassified formaldehyde as a human carcinogen (Group 1) based on epidemiological evidence that it can cause nasopharyngeal cancer in humans [18]. In several test systems, the National Institute for Occupational Safety and Health (NIOSH) [19] has demonstrated mutagenic activity in response to formaldehyde exposure. Several epidemiological studies have also reported positive associations between formaldehyde exposure and lymphohematopoietic cancers among embalmers [20] and among anatomists and pathologists [21]. Other formaldehyde-exposing occupations have been shown to be associated with leukaemia [22], Hodgkin lymphoma [23] and nasopharyngeal cancer [24] [25]. To protect workers from the acute and chronic health effects of formaldehyde exposure, several international organisations have established legal or recommended standards for the use of formaldehyde in the workplace. 
For example, the United States Occupational Safety and Health Administration (US OSHA) [26] has stipulated that the permissible formaldehyde air concentration that a worker can be exposed to over an $8-\mathrm{hr}$ day $\left(\mathrm{TWA}_{8}\right)$ is $0.75 \mathrm{ppm}$. Furthermore, the maximum formaldehyde concentration that a worker can be exposed to average over $15 \mathrm{~min}$ (short-term exposure limit, STEL) was set at 2 ppm. The Occupational Safety and Health Act Malaysia under the Use and Standards of Exposure of Chemicals Hazardous to Health Regulations [27] has established that the airborne concentration of formaldehyde should not exceed $0.3 \mathrm{ppm}$ at any time during a work shift.

In Malaysia, formaldehyde is widely used in all histopathology laboratories, where its use is crucial for preserving tissue specimens, thus making the compound unavoidable in the daily work cycle of a laboratory. However, no studies have yet investigated the exposure to formaldehyde and health symptoms among pathologists in histopathology laboratories in Malaysia. A formaldehyde concentration that exceeds the limit worsens air quality and poses an additional health hazard to workers. This study measured the formaldehyde exposure through workplace area concentrations and personal exposure levels, identified the symptoms of poor health related to formaldehyde exposure as well as estimated the risk of cancer and noncancer effects among exposed and nonexposed workers in selected hospitals.

\section{Methods}

\subsection{Study Design}

We conducted a cross-sectional comparative study involving a nonexposed group and an exposed group along with air sampling measurement. Four hospitals within Klang Valley, Selangor, Malaysia, were randomly selected for this study; these are referred to Hospitals A, B, C, and D. Air sampling and survey were performed from March to June 2015.

\subsection{Air Sampling Analysis}

\subsubsection{Formaldehyde Sampling Setting}

In each hospital, an administration office was chosen as the nonexposed area and a histopathology laboratory was chosen as the exposed area. Air sampling was conducted for determining formaldehyde workplace and personal exposure. The sampling procedure and preparation were based on the US OSHA Standard Method number 52 (OSHA 52) and NIOSH 2541. Workplace exposure was measured at both nonexposed and exposed areas during normal working hour from 8 am to 5 pm to represent the 8 -hr Time Weighted Average $\left(\mathrm{TWA}_{8}\right.$ ) concentration. Personal exposure sampling was conducted to determine the 15-min Short Term Exposure Limit (STEL) at the breathing zone of the laboratory workers. The number of STEL samples varied among respondents, depending on the duration of the respondent's presence in the laboratory, where they were likely exposed to formaldehyde. The type of activities performed by the workers 
was observed during each STEL sampling. Control facilities that were implemented in each laboratory were remarked.

\subsubsection{Materials and Apparatus}

Formaldehyde solution of ACS reagent grade, $37 \mathrm{wt} \%$ in $\mathrm{H}_{2} \mathrm{O}$ (Sigma Aldrich Corporation, Burlington, MA, USA), was used as the internal standard. Methanol SupraSolv (Merck \& Co, Inc., Kenilworth, NJ, USA), toluene (Merck \& Co., Inc.), and N-N dimethylformamide (99.5\%; R\&M Chemicals Ltd., London, UK) were used for the analysis. The sampling sorbent used was XAD-2 (2 hydroxymethyl piperidine) in a 75/150 $\mathrm{mg}$ glass tube $(110 \mathrm{~mm}$ long; $6 \mathrm{~mm}$ outer diameter; $4 \mathrm{~mm}$ inner diameter; SKC Inc., Eighty Four, PA, USA). Also utilised was a personal sampling pump (AirChek XR5000, model 210-5000, SKC Inc.) with a 0.01 to $0.10 \mathrm{~L} \cdot \mathrm{min}^{-1}$ flow rate and flexible connecting tubing, low-flow tube holder, protective tube cover, collar clip, and pump pouch. An air flow calibrator was used to calibrate the pump prior to and after each sampling session (Bios Defender 510, serial No. 117011, model No. 510-M, Bios International Corp., Butler, NJ, USA).

\subsubsection{Formaldehyde Workplace Sampling}

Sampling tubes were clipped onto a tripod at a height of $1.5 \mathrm{~m}$ of the sampling area, and the pump flow was set as recommended in the OSHA 52 method at 0.1 $\mathrm{L} \cdot \mathrm{min}^{-1}$ for $240 \mathrm{~min}$, with a total of $24 \mathrm{~L}$ of air volume. Each sampling pump was calibrated before use. The pump with the representative sampling media was calibrated to ensure that the flow did not change by more than 5\%. At least three blanks for each sampling site were included. The field blanks were handled in the same manner as the samples (open, seal, and transport) except that no air was drawn through them. Samples were stored at ambient temperature and analysed within 21 days to ensure that the stability period of the sample was not exceeded.

\subsubsection{Formaldehyde Personal Exposure Sampling}

Sorbent tube was clipped onto the worker's clothes within the breathing zone, and connected to a sampling pump using a flexible tube. The pump was placed in a pouch, worn by the worker around the waist. The sorbent tube was attached in a vertical manner such that it did not impede work performance. Samples were collected at $0.2 \mathrm{~L} \cdot \mathrm{min}^{-1}$ for $15 \mathrm{~min}$ up to a total of $3 \mathrm{~L}$ of air volume. The procedures for conducting the pump calibration, handling blank samples and transportation conditions were the same as those for the workplace air sampling.

\subsubsection{Analysis of Formaldehyde}

The front section $(150 \mathrm{mg})$ of the sampling tube was transferred to a $2-\mathrm{mL}$ vial, whereas the back section $(75 \mathrm{mg}$ ) was placed in a separate vial. Desorbing solution with an internal standard was prepared by adding $20 \mu \mathrm{L}$ of dimethylformamide to $100 \mathrm{~mL}$ of toluene; $1 \mathrm{~mL}$ of desorbing solution was added into each vial. The vials were then sealed with crimp caps, placed in an ultrasonic bath, and al- 
lowed to desorb for $1 \mathrm{hr}$ prior to analysis. The analysis was conducted using a gas chromatograph (GC)-flame ionisation detector 6890 (Agilent Technologies Inc., USA). The separation was accomplished on a GC capillary column measuring $30 \mathrm{~m} \times 0.32 \mathrm{~mm}$ with $0.5 \mu \mathrm{m}$ film. Stock standards containing $8.1 \mathrm{mg} \cdot \mathrm{mL}^{-1}$ formaldehyde were prepared by adding $1 \mathrm{~mL}$ of the $37 \%$ reagent to $50 \mathrm{~mL}$ of methanol. The acid titration method was used to determine the formaldehyde concentration. Internal standards of different concentrations $(1,2,5,15,30,60$, and $\left.120 \mu \mathrm{g} \cdot \mathrm{mL}^{-1}\right)$ were prepared to generate the calibration curve $(\mathrm{R}=0.999)$. The analysis was conducted using the splitless mode. The detector temperature was set at $250^{\circ} \mathrm{C}$, and the pressure was $0.67 \mathrm{~atm}$. The hydrogen flow rate $(99 \%$ purity) was set to $2 \mathrm{~mL} \cdot \mathrm{min}^{-1}$, and the air flow rate was set at $30 \mathrm{~mL} \cdot \mathrm{min}^{-1}$. The helium carrier gas (99\% purity) flow to the column was set at $29 \mathrm{~mL} \cdot \mathrm{min}^{-1}$. The initial column temperature was set at $70^{\circ} \mathrm{C}$, held for $2 \mathrm{~min}$, and then increased by $15^{\circ} \mathrm{C} \mathrm{min}^{-1}$ to $240^{\circ} \mathrm{C}$ for $2 \mathrm{~min}$ for a total run time of $14 \mathrm{~min}$. The conversion factor for formaldehyde used throughout this study was $1 \mathrm{ppm}=1.23 \mathrm{mg} \cdot \mathrm{m}^{-3}$ $\left(25^{\circ} \mathrm{C} ; 1 \mathrm{~atm}\right)$.

\subsection{Survey}

\subsubsection{Respondents}

Respondents were recruited among the healthcare workers in the hospitals; the exposed group comprised the laboratory workers handling formaldehyde in the histopathology laboratory, whereas the control group comprised administration workers in the same hospital who were not exposed to formaldehyde, sterilising agents, anaesthetic gases, or X-rays as part of their job requirements. Nonhealthcare workers such as contractors, cleaners, and noncitizens, were not included in this survey.

\subsubsection{Sample Size}

Sample size for the survey was calculated using the Power and Sample Size Program software (PS version 3.0.43). Cross-sectional study design sample size was calculated using the dichotomous calculation with independent, prospective, two proportions and uncorrected chi-square test design. The power of the study which was the probability rejecting the null hypothesis was $80 \%$ with a precision of $(\alpha) 0.05$ at $95 \%$ confidence level. Independent cases and controls with 4 control(s) per case were used. Sample size was calculated based on an epidemiology study [28] where the $\mathrm{p}_{0}$ value was $6 \%$ and the $\mathrm{p}_{1}$ value was $24 \%$. Based on the sample size calculation, 142 from the nonexposed group and 38 from the exposed group were chosen to be the respondents in this study.

\subsubsection{Questionnaire}

A questionnaire was constructed on the basis of pre-existing, published questionnaires on formaldehyde exposure and indoor air quality [29] [30] [31]. The self-administered questionnaire was completed by respondents in both groups. Survey comprised items on demographic characteristics; medical history on existing health problems and if under treatment; occupational history on current 
job and years in job; exposure information on average duration and frequency of exposure to formaldehyde as well as controls used and ten (10) symptoms related to formaldehyde exposure during working hour and off-working hour.

\subsection{Data Analysis}

Statistical analysis was performed using IBM SPSS Statistics Software (version 16, SPSS Inc., USA). First, descriptive statistics were calculated to explore and describe the data. Associations between categorical data for symptoms and formaldehyde concentration were then assessed using the chi square or Fisher's exact test. All statistical tests were conducted at a $95 \%$ confidence interval, using $\mathrm{p}$ $=0.05$.

\subsection{Risk Estimation}

Estimation of health risk due to inhalation of formaldehyde was evaluated for both noncarcinogenic and carcinogenic effects by following the approach used by the US EPA. The Risk Assessment Guidance for Superfund Volume I: Human Health Evaluation Manual, Parts A [32] and F [33], were employed in the risk assessment evaluation. The exposure concentration (EC) for both noncancer risk (estimated over an average time equal to the duration of assumed exposure) and cancer risk (estimated over an average time equal to an entire lifespan) were calculated using Equation (1):

$$
\mathrm{EC}=\frac{\mathrm{C} \times \mathrm{ET} \times \mathrm{EF} \times \mathrm{ED}}{\mathrm{AT}}
$$

The potential noncancer human health risk was quantified by calculating the noncancer hazard quotient (HQ) using Equation (2). Other equation parameters and values are in Table 1.

$$
\mathrm{HQ}=\frac{\mathrm{EC}}{\mathrm{RfC} \times 1000}
$$

Table 1. Variable risk factors.

\begin{tabular}{cccc}
\hline Variable & Definition & Unit & Source \\
\hline C & $\begin{array}{c}\text { Formaldehyde } \\
\text { concentration in air }\end{array}$ & $\mu \mathrm{g} \cdot \mathrm{m}^{-3}$ & TWA $_{8}$; STEL from sampling \\
ET & Exposure time & hour day ${ }^{-1}$ & 8 (normal working hour) \\
EF & Exposure frequency & days year ${ }^{-1}$ & $225\left(5\right.$ days week $^{-1}$ for 45 weeks year $\left.^{-1}\right)$ \\
ED & Exposure duration & years & $30[28]$ \\
AT & Averaging time & days & ED $\times 365$ days year $^{-1}($ noncancer $) ;^{-1}$ (cancer) \\
RfC & Inhalation & $\mu \mathrm{g} \cdot \mathrm{m}^{-3}$ & $3.94 \times 10^{-5}[32]$ \\
IUR & Inhalation unit risk & $\left(\mu \mathrm{g} \cdot \mathrm{m}^{-3}\right)^{-1}$ & $1.3 \times 10^{-5}[34]$ \\
\hline
\end{tabular}


HQ denotes the ratio of the exposure level to the reference concentration $(\mathrm{RfC})\left(\mu \mathrm{g} \cdot \mathrm{m}^{-3}\right)$. RfC represents an estimation of the extent of continuous exposure through inhalation that causes harmful noncancer health effects during a person's lifetime. The RfC value for formaldehyde was not assessed under the US EPA Integrated Risk Information System (IRIS) programme, and was therefore not available [34]. However, the draft IRIS assessment has proposed several RfCs for formaldehyde on the basis of several epidemiologic studies of related health effects. For this study, the RfC chosen was $3.94 \times 10^{-5} \mu \mathrm{g} \cdot \mathrm{m}^{-3}$; based on that in Liu et al. [35], where the RfC was derived for sensory irritation of the eye through a residential epidemiologic study that is considered one of the best available [36]. An HQ that exceeds 1 is interpreted as evidence of potential noncarcinogenic effects; by contrast, an HQ of less than 1 indicates a negligible risk of adverse health effects.

According to the Guidelines for Carcinogen Risk Assessment [37], formaldehyde is a probable human carcinogen (group B1). The characterisation and interpretation of cancer risk were determined using Equation (3), by estimating the excess lifetime probability of cancer risk (ELCR).

$$
\mathrm{ELCR}=\mathrm{EC} \times \mathrm{IUR}
$$

The inhalation unit risk (IUR) was defined as the excess risk for an individual resulting from a chronic lifetime's exposure (70 years) to one unit of pollutant concentration (1 $\left.\mu \mathrm{g} \cdot \mathrm{m}^{-3}\right)$ [37] [38] [39] [40]. The acceptable limit of ELCR, as defined by the US EPA, is $10^{-4}$ [41] where any value equal to or less than $10^{-4}$ represents an acceptable level of risk.

\subsection{Ethical Considerations}

This study was approved by the Medical Research and Ethics Committee, Ministry of Health Malaysia.

\section{Results}

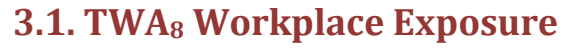

The $\mathrm{TWA}_{8}$ concentrations of formaldehyde in histopathology laboratories were higher with an average of $0.252 \pm 0.105 \mathrm{ppm}$ than the administration offices, for which the average was $0.076 \pm 0.016 \mathrm{ppm}$. Table 2 summarizes results of the $\mathrm{TWA}_{8}$ concentrations measured in both areas of the four hospitals. These results indicated that the laboratory workers were exposed to $140 \%-480 \%$ higher concentrations of formaldehyde than the administration workers. Although higher, these concentrations were nevertheless below the US OSHA permissible exposure limit of $0.75 \mathrm{ppm}$ for workplace formaldehyde exposure. For administration offices, the concentrations of formaldehyde recorded were less than the limit set by the Malaysia Industry Code of Practice on Indoor Air Quality 2010 (ICOP) [42] of $0.1 \mathrm{ppm}$.

Environmental control facilities were implemented in each of the laboratory, such as ducted backdraft grossing station (Hospitals A and B), recirculating 
Table 2. The TWA $(\mathrm{ppm})$ concentrations of formaldehyde measured at nonexposed and exposed areas of each hospital.

\begin{tabular}{rcc}
\hline & $\begin{array}{c}\text { Nonexposed area } \\
\text { (Administration office) }\end{array}$ & $\begin{array}{c}\text { Exposed area } \\
\text { (Histopathology laboratory) }\end{array}$ \\
\cline { 2 - 3 } & $\mathrm{TWA}_{8}(\mathrm{ppm})$ & $\mathrm{TWA}_{8}(\mathrm{ppm})$ \\
\hline Hospital A & 0.088 & 0.215 \\
Hospital B & 0.055 & 0.154 \\
Hospital C & 0.088 & 0.239 \\
Hospital D & 0.072 & 0.400 \\
Reference limit (ppm) & $0.100^{\mathrm{a}}$ & $0.750^{\mathrm{b}}$ \\
\hline
\end{tabular}

a. Malaysia Industry Code of Practice on Indoor Air Quality (ICOP) Department of Occupational Safety and Health Malaysia, 2010 [42]; b. United States Occupational Safety and Health Administration (US OSHA) Permissible Exposure Limit (PEL), 1993 [26].

backdraft grossing station (Hospitals $\mathrm{C}$ and $\mathrm{D}$ ), fume hood (Hospital A), mechanical exhaust ventilation (Hospital B), and proper chemical storage (Hospitals $A$ and $B$ ) (Table 3). Hospital $B$ had a spacious grossing area $\left(53 \mathrm{~m}^{2}\right)$, while other laboratories in Hospitals $\mathrm{A}, \mathrm{C}$ and $\mathrm{D}$ had smaller grossing room $\left(\leq 20 \mathrm{~m}^{2}\right)$.

\subsection{STEL Personal Exposure}

A total of 505 STEL samples were obtained from 38 histopathology laboratory workers. The STEL levels ranged between $0.018 \mathrm{ppm}$ and $2.251 \mathrm{ppm}$. Personal exposure to formaldehyde was highest during the grossing activity $(0.797 \pm$ $0.436 \mathrm{ppm})$, and lowest during slide examination $(0.225 \pm 0.092 \mathrm{ppm})$ (Table 4). A large proportion (501 of 505, 99.2\%) of the STEL samples were below the US OSHA [29] recommended STEL limit of 2 ppm. Four (4) of the $505(0.8 \%)$ samples exceeded the OSHA limit. From the observation, three (3) of the STEL samples, which exceeded the limit were obtained during tissue fixation (grossing), and one (1) sample was during receiving specimens.

\subsection{Survey and Health Symptoms}

The total number of survey respondents was 178, with 142 from the nonexposed group and 38 from the exposed group. The characteristics of both groups are presented in Table 5. Most of the participants in both the nonexposed and exposed groups were women, $79.6 \%$ and $76.3 \%$, respectively. A total of $79.7 \%$ of the respondents were aged from 21 to 39 years. Regarding occupation, $91.5 \%$ of the nonexposed group were general workers or clerks whereas $75 \%$ of the exposed group were medical laboratory technologists and $16.7 \%$ were medical of ficers. More than $70 \%$ of the respondents had worked for 2 to 10 years at the same hospital.

From the information on the formaldehyde exposure, $78 \%$ of the laboratory workers did not handle formaldehyde under the local exhaust ventilation (LEV) when handling the specimens for processes other than grossing. In terms of hand protection, $79.4 \%$ of the respondents used latex gloves whereas $20.6 \%$ did 
Table 3. Environmental control facilities in histopathology laboratories of each hospital.

\begin{tabular}{ccccc}
\hline Type of facilities & Hospital A & Hospital B & Hospital C Hospital D \\
\hline Grossing area, $\left(\mathrm{m}^{2}\right)$ & 20 & 53 & 10 & 18 \\
$\begin{array}{c}\text { Ducted backdraft grossing station, (unit) } \\
\text { Recirculating backdraft grosiing station, (unit) }\end{array}$ & 1 & 1 & N/a & N/a \\
Fume hood, (unit) & 2 & N/a & 1 & 1 \\
Nechanical exhaust ventilation, (unit) & N/a & 1 & N/a & N/a $/ a$ \\
Usual fan, (unit) & 1 & N/a & N/a & N/a \\
Split unit air conditioner, (unit) & 2 & 2 & N/a & 2 \\
Centralized air conditioner, (unit) & Yes & No & Yes & Yes \\
Outdoor air getting into & No & No & No & No \\
workplace through windows & Yes & Yes & No & No \\
Proper chemical/specimen storage & & & & \\
\hline
\end{tabular}

N/a: not available.

Table 4. The STEL concentrations of formaldehyde based on the work tasks, the number of samples, and maximum and minimum concentrations.

\begin{tabular}{cccc}
\hline Tasks & $\mathrm{N}$ & $\begin{array}{c}\text { STEL }(\mathrm{ppm}) \\
\text { Mean } \pm\end{array}$ & $\begin{array}{c}\text { Min }- \text { Max } \\
(\mathrm{ppm})\end{array}$ \\
\hline Grossing & 86 & $0.797 \pm 0.436$ & $0.093-2.251$ \\
Receiving specimen & 108 & $0.420 \pm 0.299$ & $0.066-2.108$ \\
Preparation at grossing area & 131 & $0.395 \pm 0.295$ & $0.079-1.463$ \\
Sectioning & 60 & $0.393 \pm 0.244$ & $0.024-0.940$ \\
Embedding & 53 & $0.287 \pm 0.197$ & $0.019-0.810$ \\
Staining & 49 & $0.281 \pm 0.191$ & $0.018-0.908$ \\
Slide examination & 18 & $0.225 \pm 0.092$ & $0.087-0.410$ \\
Reference limit & - & $2.000^{\mathrm{a}}$ & \\
\hline
\end{tabular}

a. United States Occupational Safety and Health Administration (US OSHA) Permissible Exposure Limit (PEL), 1993 [26].

Table 5. Social demography characteristics (gender, age group, years of employment, and job title) of nonexposed and exposed groups.

\begin{tabular}{ccc}
\hline & $\begin{array}{c}\text { Nonexposed group } \\
\text { (Administration workers) } \\
\mathrm{n}(\%)\end{array}$ & $\begin{array}{c}\text { Exposed group } \\
\text { (Laboratory workers) } \\
\mathrm{n}(\%)\end{array}$ \\
Gender & $113(79.6)$ & $29(76.3)$ \\
Female & $29(20.4)$ & $9(23.7)$ \\
Male & & $16(44.4)$ \\
Age group & $50(35.2)$ & $16(4.4)$ \\
$21-29$ & $60(42.3)$ & \\
$30-39$ & &
\end{tabular}




\begin{tabular}{|c|c|c|}
\hline \multicolumn{3}{|l|}{ Continued } \\
\hline $40-49$ & $15(10.6)$ & $2(5.6)$ \\
\hline $50-59$ & $17(12.0)$ & $2(5.6)$ \\
\hline \multicolumn{3}{|l|}{ Years of employment } \\
\hline$<1$ & $21(14.8)$ & $7(19.4)$ \\
\hline $2-5$ & $48(33.8)$ & $16(44.4)$ \\
\hline $6-10$ & $50(35.2)$ & $9(250)$ \\
\hline $11-15$ & $11(7.7)$ & $2(5.6)$ \\
\hline $16-25$ & $9(6.3)$ & $1(2.8)$ \\
\hline $25>$ & $3(2.1)$ & $1(2.8)$ \\
\hline \multicolumn{3}{|l|}{ Job title } \\
\hline Medical laboratory technologist & - & $27(75.0)$ \\
\hline Medical officer & - & $6(16.7)$ \\
\hline Science officer & - & $1(2.8)$ \\
\hline Attendant & - & $2(5.6)$ \\
\hline Accountant & $2(1.4)$ & \\
\hline Clerk & $129(91.5)$ & \\
\hline Others & $10(7.1)$ & \\
\hline
\end{tabular}

not use any glove. Nitrile gloves were also used by $50 \%$ of the respondents. For inhalation protection, surgical mask, an N95 type respirator and an R95 type respirator was worn by $93.8 \%, 31.8 \%$ and $9.5 \%$, respectively. The most suitable form of inhalation protection was half-face respiratory protection with respirator cartridges approved for use against formaldehyde organic vapour. This respirator was used by $65.4 \%$ of the respondents. More than $77 \%$ of the exposed workers claimed they were exposed to formaldehyde specimens every day.

Up to $67 \%$ of the exposed group and $57 \%$ of the nonexposed group reported having symptoms while employed at their current workplace (Table 6). The most likely symptom to be experienced by both groups was strained eyes $(>57 \%)$, and the least experienced was shortness of breath $(<10 \%)$. Four symptoms (eye irritation, headache, drowsiness, and chest tightness) were significantly more common in the exposed group than in the nonexposed group ( $\mathrm{p}<$ 0.05). Among those with symptoms, up to $37 \%$ of the exposed workers and $16 \%$ of the nonexposed workers believed that the symptoms were related to their current workplace environment and the symptoms improved during nonworking hours.

\subsection{Risk Assessment}

The health risks of formaldehyde exposure for both groups were estimated using ELCR and HQ (Table 7). The cancer risks (ELCR) for both groups and for all work activities were considerably lower than the acceptable carcinogenic risk 
Table 6. Percentage of nonexposed and exposed group claimed having the symptoms, and Pearson Chi Square test for respondent answer "Yes" for having symptoms related to work and become better when off-work.

\begin{tabular}{|c|c|c|c|c|c|c|c|c|}
\hline & \multicolumn{4}{|c|}{ Respondent answer "Yes" for having symptoms } & \multicolumn{4}{|c|}{$\begin{array}{l}\text { Respondent answer "Yes" for having symptoms AND "Yes" } \\
\text { it is related to work AND "Yes" it become better when off-work }\end{array}$} \\
\hline & $\begin{array}{c}\text { Nonexposed } \\
\text { Group \% }\end{array}$ & $\begin{array}{l}\text { Exposed } \\
\text { Group \% }\end{array}$ & $X^{2}(1)$ & $\mathrm{p}$ & $\begin{array}{c}\text { Nonexposed } \\
\text { Group \% }\end{array}$ & $\begin{array}{l}\text { Exposed } \\
\text { Group \% }\end{array}$ & $\begin{array}{l}X^{2} \\
(1)\end{array}$ & $\mathrm{p}$ \\
\hline Strained eyes & 57.0 & 66.7 & 1.10 & 0.294 & 38.0 & 47.4 & 1.090 & 0.297 \\
\hline Eyes irritation & 19.0 & 41.7 & 8.17 & $0.004^{\mathrm{a}}$ & 24.6 & 50.0 & 9.175 & $0.002^{\mathrm{a}}$ \\
\hline Headache & 34.5 & 55.6 & 5.360 & $0.021^{\mathrm{a}}$ & 14.1 & 34.2 & 8.110 & $0.004^{\mathrm{a}}$ \\
\hline Drowsiness & 32.4 & 52.8 & 5.147 & $0.023^{\mathrm{a}}$ & 16.2 & 36.8 & 7.824 & $0.005^{\mathrm{a}}$ \\
\hline Sore or dry throat & 35.2 & 41.7 & 0.516 & 0.472 & 13.4 & 34.2 & 8.899 & $0.003^{\mathrm{a}}$ \\
\hline Runny nose & 24.6 & 33.3 & 1.115 & 0.291 & 6.3 & 18.4 & & $0.047^{\mathrm{b}}$ \\
\hline Chest tightness & 7.7 & 22.2 & & $0.029^{b}$ & 1.4 & 21.1 & & $<0.001^{\mathrm{b}}$ \\
\hline Cough & 27.5 & 25.0 & 0.089 & 0.766 & 7.7 & 10.5 & & 0.525 \\
\hline Sneezing & 21.1 & 8.3 & 3.112 & 0.078 & 9.9 & 5.3 & & 0.529 \\
\hline Shortness of breath & 9.9 & 8.3 & & 1.00 & 3.5 & 7.9 & & 0.368 \\
\hline
\end{tabular}

a. Pearson Chi Square Test, $\mathrm{p}<0.05$; b. Fisher's Exact Test, $\mathrm{p}<0.05$.

Table 7. The calculated exposure concentration (EC) for cancer and noncancer, hazard quotient (HQ) of noncarcinogenic effects and estimated lifetime cancer risk (ELCR) for each sampling areas and work tasks by the laboratory workers.

\begin{tabular}{|c|c|c|c|c|c|}
\hline Area $\left(\mathrm{TWA}_{8}\right)$ & Sampling site & $\begin{array}{c}\mathrm{EC}_{\text {noncancer }} \\
\left(\mu \mathrm{g} \cdot \mathrm{m}^{-3}\right)\end{array}$ & HQ & $\begin{array}{l}\mathrm{EC}_{\text {cancer }} \\
\left(\mu \mathrm{g} \cdot \mathrm{m}^{-3}\right)\end{array}$ & ELCR \\
\hline \multirow{4}{*}{ Administration offices } & Hospital A & $2.3 \mathrm{E}-5$ & 0.57 & $1.0 \mathrm{E}-5$ & 7..46E-9 \\
\hline & Hospital B & $1.4 \mathrm{E}-5$ & 0.35 & $6.0 \mathrm{E}-6$ & $4.58 \mathrm{E}-9$ \\
\hline & Hospital C & $2.3 \mathrm{E}-5$ & 0.57 & $1.0 \mathrm{E}-5$ & $7.46 \mathrm{E}-9$ \\
\hline & Hospital D & $1.8 \mathrm{E}-5$ & 0.46 & $8.0 \mathrm{E}-6$ & $5.99 \mathrm{E}-9$ \\
\hline \multirow{4}{*}{ Laboratories } & Hospital A & $5.3 \mathrm{E}-5$ & 1.36 & $2.3 \mathrm{E}-5$ & $1.76 \mathrm{E}-8$ \\
\hline & Hospital B & $3.9 \mathrm{E}-5$ & 0.99 & $1.7 \mathrm{E}-5$ & $1.29 \mathrm{E}-8$ \\
\hline & Hospital C & $6.0 \mathrm{E}-5$ & 1.51 & $2.6 \mathrm{E}-5$ & $1.97 \mathrm{E}-8$ \\
\hline & Hospital D & $1.01 \mathrm{E}-4$ & 2.56 & $4.3 \mathrm{E}-5$ & $3.32 \mathrm{E}-8$ \\
\hline \multicolumn{2}{|l|}{ Work activity (STEL) } & $\begin{array}{c}\mathrm{EC}_{\text {noncancer }} \\
\left(\mu \mathrm{g} \cdot \mathrm{m}^{-3}\right)\end{array}$ & HQ & $\begin{array}{l}\mathrm{EC}_{\text {cancer }} \\
\left(\mu \mathrm{g} \cdot \mathrm{m}^{-3}\right)\end{array}$ & ELCR \\
\hline \multicolumn{2}{|l|}{ Grossing } & $1.64 \mathrm{E}-4$ & 4.16 & $8.63 \mathrm{E}-5$ & $5.40 \mathrm{E}-8$ \\
\hline \multicolumn{2}{|l|}{ Receiving specimens } & $8.63 \mathrm{E}-5$ & 2.19 & $4.55 \mathrm{E}-5$ & $2.85 \mathrm{E}-8$ \\
\hline \multicolumn{2}{|l|}{ Preparation at grossing area } & $8.12 \mathrm{E}-5$ & 2.06 & $4.28 \mathrm{E}-5$ & $2.68 \mathrm{E}-8$ \\
\hline \multicolumn{2}{|l|}{ Sectioning } & $8.08 \mathrm{E}-5$ & 2.05 & $4.26 \mathrm{E}-5$ & $2.66 \mathrm{E}-8$ \\
\hline \multicolumn{2}{|l|}{ Embedding } & $5.90 \mathrm{E}-5$ & 1.50 & $3.11 \mathrm{E}-5$ & $1.95 \mathrm{E}-8$ \\
\hline \multicolumn{2}{|l|}{ Staining } & $5.77 \mathrm{E}-5$ & 1.47 & $3.04 \mathrm{E}-5$ & $1.91 \mathrm{E}-8$ \\
\hline \multicolumn{2}{|l|}{ Slide examination } & $4.62 \mathrm{E}-5$ & 1.17 & $2.44 \mathrm{E}-5$ & $1.53 \mathrm{E}-8$ \\
\hline
\end{tabular}


limit of $10^{-4}$. These values indicated that the laboratory and office workers had a low or negligible cancer risk following formaldehyde exposure at their workplace. However, the ELCR were 2 to 4 times higher in the laboratory areas than in the administration offices. The risk of suffering noncarcinogenic chronic effects (eye irritation) was evaluated using HQ. All the estimated HQs for the administration offices were lower than 1. This indicated negligible risk of adverse health effects in the nonexposed group. However, the estimated HQ was higher for the laboratory areas, being higher than 1 for three laboratories (those in Hospitals A, C, and D). The HQs for all work activities performed by the laboratory workers were higher than 1, and grossing activity had the highest HQ of 4.16.

\section{Discussion}

Generally, formaldehyde was presence in both nonexposed and exposed areas. The presence of formaldehyde in the workplace environment of the nonexposed areas might be attributed to several possible sources, including pressed wood products, adhesives, varnishes, furniture, carpet, and other indoor products [43] [44], all of which are common in administration offices. The use of formaldehyde is a common practice in histopathology laboratories for preservation of human specimens in Malaysia. Formaldehyde vapours are emitted from various laboratory activities resulting in laboratory workers being exposed to elevated levels of formaldehyde. Numerous studies have been conducted in various countries on occupational formaldehyde exposure in hospital environments (anatomy, histopathology, and pathology laboratories) (Table 8). This study is most similar to that of Ladeira et al. [45] in terms of methodology and sampling site. The $\mathrm{TWA}_{8}$ concentrations of formaldehyde reported in this study $(0.076$ -

Table 8. Formaldehyde concentrations in samples related to occupational formaldehyde exposure in hospital environment in other studies.

\begin{tabular}{|c|c|c|c|c|}
\hline Location & Method & Sampling area & Concentrations (ppm) & Reference \\
\hline Klang valley, Malaysia & OSHA 52 and NIOSH 2541 & Histopathology laboratory & $\begin{array}{c}0.076-0.252\left(\mathrm{TWA}_{8}\right) \\
0.018-2.953(\mathrm{STEL})\end{array}$ & This study \\
\hline Cagayan de Oro, Philippines & DNPH and DNPH-coated silica & Histopathology laboratory & $0.14-1.03\left(\mathrm{TWA}_{8}\right)$ & {$[4]$} \\
\hline Selangor, Malaysia & NIOSH 2541 & Anatomy laboratory & $\begin{array}{c}0.10-0.17\left(\mathrm{TWA}_{8}\right) \\
2.30(\mathrm{STEL})\end{array}$ & {$[6]$} \\
\hline Tehran, Iran & NIOSH 2016 & Anatomy laboratory & $0.306-0.698$ (STEL) & {$[48]$} \\
\hline Piedmont region, Italy & NIOSH 2016 & Pathology laboratory & $0.012-0.454\left(\mathrm{TWA}_{8}\right)$ & {$[1]$} \\
\hline $\begin{array}{l}\text { University of Sharjah, } \\
\text { United Arab Emirates }\end{array}$ & NIOSH 3500 & Anatomy laboratory & $0.013-0.105\left(\mathrm{TWA}_{8}\right)$ & {$[46]$} \\
\hline South of France & Passive air monitoring badges & Pathology and anatomy laboratory & $\begin{array}{l}0.1-0.7\left(\mathrm{TWA}_{8}\right) \\
0.1-20.4(\mathrm{STEL})\end{array}$ & {$[15]$} \\
\hline Tehran, Iran & NIOSH 3500 & Pathology laboratory & $0.73-1.19\left(\mathrm{TWA}_{8}\right)$ & {$[14]$} \\
\hline
\end{tabular}


$0.252 \mathrm{ppm}$ ) was also within the range of values measured in their study [45] which was 0.04 to $0.51 \mathrm{ppm}$. Other studies [1] [6] [46] have obtained similar results, with $\mathrm{TWA}_{8}$ concentrations ranging from 0.012 to $0.454 \mathrm{ppm}$. By contrast, others [4] [15] obtained considerably higher $\mathrm{TWA}_{8}$ ranging from 0.10 to 1.19 ppm whereas Ghasemkhani et al. [14] found that the concentration of formaldehyde in pathology laboratories exceeded the recommended limits. This paper discovered that formaldehyde level might be strongly influenced by the control measures, workspace, and setting. This was demonstrated by the fact that the $\mathrm{TWA}_{8}$ and STEL concentrations were lower for Hospitals A and B (applied ducted backdraft grossing station, fume hoods, mechanical exhaust ventilator and proper specimen storage), compared with Hospitals C and D, which had fewer control measures (smaller grossing area, recirculating backdraft grossing station, no mechanical exhaust ventilation, and no proper specimen storage). Wenhai and Erica [47] explored the effectiveness of five ventilation systems in reducing formaldehyde exposure in anatomic pathology laboratories. They found that ducted backdraft grossing stations were the most effective systems and recommended using these to control formaldehyde exposure during gross examination rather than other types of grossing station. Improper processing controls such as LEV in pathology laboratories were the major reasons for increased formaldehyde level in the sampling areas [14] [15] [48].

The specific work activity performed by the laboratory workers was found to influence the personal levels of formaldehyde exposure. Workers performing grossing activity showed the highest mean STEL concentrations, compared with those conducting other activities. Several studies [4] [14] [15] [49] also detected high levels of formaldehyde during the gross-cutting task. Takigawa et al. [12] suggested that the level of personal exposure to formaldehyde for a person who is performing dissection may be 2 to 3 times greater than the mean ambient formaldehyde concentration. During grossing, workers were in a sitting position and the formaldehyde-soaked specimens were very close to the breathing zone of the workers throughout this procedure. Although formaldehyde exposure was high during grossing, observation showed that the laboratory workers wore appropriate respiratory protection with a formaldehyde cartridge filter and performed the task under a fume hood, which helps reduce exposure through inhalation. The STEL concentrations recorded in this study (0.018 - $2.953 \mathrm{ppm})$ were broadly the same as those determined by Ya'acob et al. [6] (2.30 ppm), who adopted a similar methodology (NIOSH 2541) to this paper. By contrast, Azari et al. [50] found STEL concentrations ( 0.306 to $0.698 \mathrm{ppm}$ ) lower than those in this study. This might be due to the ventilation system (supply-exhaust) applied, that reduced the formaldehyde concentrations by up to $56 \%$.

Health symptoms were reported in both nonexposed and exposed groups. Symptoms reported among the administration workers might due to their nature of job, as more than $91 \%$ were office workers or clerks, whose exposed daily to a photocopy machine, laser printer, or fax machine. These machines also emit various volatile organic compounds (VOCs) including formaldehyde [45]. The 
workers were exposed to these VOCs during their routine tasks, which might therefore have been the cause of their symptoms. In this study, eye irritation, headache, chest tightness, and runny nose were significantly higher among the laboratory workers, who were exposed to higher levels of formaldehyde than the nonexposed workers. Irritation of the eyes and upper airway is a critical indicator of the acute effects of formaldehyde [3]. The WHO [3] stated that the lowest formaldehyde concentration reported to cause eye irritation in humans is 0.293 ppm for 4 hours; this explains the significant eye irritation symptoms in this study as the laboratory workers were exposed to higher amounts of formaldehyde. Other study [6] identified eye and nose irritation as the most commonly reported symptoms (55\%) arising from formaldehyde exposure during dissection in an anatomy laboratory. More than $50 \%$ of exposed staff in an anatomy laboratory reported a cough, throat irritation, and a runny nose while $48 \%$ experienced eye irritation [50]. Other had reported similar results and a significant difference between the prevalence of eye irritation, nose irritation, shortness of breath, headache, dry throat, and chest tightness during hours spent in dissection compared with nonworking hour [6]. In terms of PPE used, latex gloves, a 3-ply mask, a plastic coat, a lab coat, and cover shoes were often used by the laboratory workers, although these are not suitable for handling formaldehyde. The use of inappropriate PPEs had failed as a control equipment in minimising exposure to formaldehyde in the laboratory. Sensitivity to the odour of formaldehyde and subsequent eye irritation decrease over time as an individual adapts to formaldehyde exposure. This can lead to overexposure if a worker expects the normal properties of formaldehyde to alert them to potential exposure [51].

Although symptoms were present in both groups, the noncancer risk due to inhalation was negligible among the nonexposed workers, while a significantly higher percentage of exposed workers experienced eye irritation (HQ was $>1$ ). Although the risks were higher in exposed areas than in nonexposed areas, these results raise a significant concern regarding health effects in both workplace environments. Because the estimation of HQ was derived from an epidemiology study (no established values are yet available), the estimation is considered conservative and might even underestimate the risk. The estimated cancer risk shows that both groups have a very low risk of developing cancer as a result of lifelong exposure to formaldehyde, because all risk values were below the acceptable cancer risk of $10^{-4}$ defined by the US EPA [37]. Although several studies have identified an association between formaldehyde exposure and cancers such as leukaemia [22] [23], other cohort study found no associations between peak or cumulative formaldehyde exposure and risk of specific lymphohematopoietic malignancies including acute myeloid leukaemia, chronic myeloid leukaemia, Hodgkin lymphoma, and chronic lymphocytic leukaemia [52]. However, the risk may increase if the efficacy of existing control measures deteriorates. This may include failure of control equipment/systems and PPE; human error due to lack of awareness, failure of monitoring, or inadequate training; improper use of control measures; changes in work activities; and a significant increase in the 
quantity of specimens/formaldehyde used.

Although every effort was made to minimise biases and flaws in the study, the following limitations were acknowledged when interpreting the results. A cross-sectional study provides only a snapshot of health status and thus cannot reveal causal associations. The survey also assumed that exposure to environmental hazards was constant throughout the year. In self-report surveys, recall bias exists; however, this was minimised by using a short recall period. This measurement, however, can only capture the level of exposure in the workplace and does not capture exposure at home or during off-duty hour. Despite these limitations, the sample size was adequate to give valid results and supported by many studies.

\section{Conclusion}

In conclusion, formaldehyde concentrations had been greatly influenced by the specific activity conducted by the workers, and the adequacy of the ventilation and engineering control systems. Despite concentrations of workplace and personal exposure to formaldehyde that were below the standard limit, symptoms of poor health were significantly higher among the exposed group, suggesting considerable exposure to formaldehyde. This evidence was strengthened by the estimated risk of noncancer chronic effects, which indicate a potential risk of eye irritation among laboratory workers. Formaldehyde is also known as carcinogenic; however, the cancer risk was not significant in both groups. Based on the findings and evaluation, several control measures can be implemented to minimise the risks associated with formaldehyde exposure among workers as both practice and environment were concluded to contribute to the level of formaldehyde. Further control measures might be considered along with the existing controls for an effective protection such as best work practice, and enhancing awareness and training [48] [49]. For example, chemical bottles should be stored away from the work area in a chemical store or chemical cabinet when not in use. Most of the sampling sites were located in an open area also used for receiving specimens. All specimens were placed in nonairtight containers from which formaldehyde vapour may diffuse to the working environment. A screw cap container, which is leak resistant and airtight, is therefore recommended when placing specimens containing formaldehyde because this will reduce the amount of formaldehyde released into the air. All specimens should be kept isolated in a designated room away from the work area, as implemented in Hospitals $\mathrm{A}$ and $\mathrm{B}$, or kept in a formalin storage cabinet before they are disposed. Such measures of both engineering control and best work practice will help minimise the potential health risks to the workers.

\section{Acknowledgements}

The authors would like to gratefully acknowledge the financial support from Ministry of Health Malaysia Malaysia (grant number NMRR-14-217-20234) and 
to the Director General of Health Malaysia for the permission to publish. We would like to extend our sincere gratitude to all relevant hospitals for their cooperation and support, to Environmental Health Research Centre and Entomology Unit, Institute for Medical Research (IMR), Malaysia who gave us permission to use all the required equipment and necessary materials to complete the task. This manuscript was edited by Wallace Academic Editing.

\section{Conflicts of Interest}

The authors declare no conflicts of interest regarding the publication of this paper.

\section{References}

[1] Bono, R., Romanazzi, V., Pirro, V., Degan, R., Pignata, C., Suppo, E., et al. (2012) Formaldehyde and Tobacco as Alkylating Agents: The Formation of N-Methylenvaline in Pathologists and in Plastic Laminate Workers. Science of the Total Environment, 414, 701-707. https://doi.org/10.1016/j.scitotenv.2011.10.047

[2] Xu, Y. and Zhang, Y.-P. (2003) An Improved Mass Transfer Based Model for Analyzing VOC Emission from Building Materials. Atmospheric Environment, 37, 2497-2250. https://doi.org/10.1016/S1352-2310(03)00160-2

[3] World Health Organization, Regional Office for Europe (2010) WHO Guidelines for Indoor Air Quality: Selected Pollutants. World Health Organization. Regional Office for Europe. http://www.who.int/iris/handle/10665/260127

[4] Jerusalem, J.G., and Galarpe, V.R.K.R. (2015) Determination of Formaldehyde in Air in Selected Hospital Histopathology-Laboratories in Cagayan de Oro, Philippines. Journal of Chemical Health \& Safety, 22, 10-14.

https://doi.org/10.1016/j.jchas.2014.07.012

[5] Norback, D., Hashim, J.H., Hashim, Z. and Ali, F. (2017) Volatile Organic Compound (VOC), Formaldehyde and Nitrogen Dioxide $\left(\mathrm{NO}_{2}\right)$ in Schools in Johor Bahru, Malaysia: Association with Rhinitis, Ocular, Throat and Dermal Symptoms, Headache and Fatigue. Science of the Total Environment, 592, 153-160. https://doi.org/10.1016/j.scitotenv.2017.02.215

[6] Ya'acob, S.H., Suis, A.J., Awang, N. and Sahani, M. (2013) Exposure Assessment of Formaldehyde and Its Symptoms among Anatomy Laboratory Workers and Medical Students. Asian Journal of Applied Sciences, 6, 50-55. https://doi.org/10.3923/ajaps.2013.50.55

[7] Horvath, E.P., Anderson, J., Pierce, W.E., Hanrahan, L. and Wendlick, J.D. (1988) Effects of Formaldehyde on the Mucous Membranes and Lungs: A Study of an Industrial Population. Journal of the American Medical Association, 259, 701-707. https://doi.org/10.1001/jama.1988.03720050037020

[8] World Health Organization (WHO) (1989) Environmental Health Criteria for Formaldehyde: Vol. 89. Geneva, Switzerland.

[9] Agency for Toxic Substances and Disease Registry (ATSDR) (1997) Toxicological Profile for Formaldehyde (Draft). Public Health Services, United States Department of Health and Human Services, Atlanta, GA.

[10] Feron, V.J., Arts, J.H., Kuper, C.F., Slootweg, P.J. and Woutersen, R.A. (2001) Health Risks Associated with Inhaled Nasal Toxicants. Critical Reviews in Toxicology, 31, 313-347. https://doi.org/10.1080/20014091111712 
[11] Kriebel, D., Sama, S.R. and Cocanour, B. (1993) Reversible Pulmonary Responses to Formaldehyde. A Study of Clinical Anatomy Students. American Review of Respiratory Disease, 148, 1509-1515. https://doi.org/10.1164/ajrccm/148.6_Pt_1.1509

[12] Takigawa, T., Usami, M., Yamasaki, Y., Wang, B., Sakano, N., Horike, T., et al. (2005) Reduction of Indoor Formaldehyde Concentrations and Subjective Symptoms in a Gross Anatomy Laboratory. Bulletin of Environmental Contamination and Toxicology, 74, 1027-1033. https://doi.org/10.1007/s00128-005-0683-2

[13] Takahashi, S., Tsuji, K., Fujii, K., Okazaki, F., Takigawa, T., Ohtsuka, A., et al. (2007) Prospective Study of Clinical Symptoms and Skin Test Reactions in Medical Students Exposed to Formaldehyde Gas. The Journal of Dermatology, 34, 283-289. https://doi.org/10.1111/j.1346-8138.2007.00274.x

[14] Ghasmenkhani, M., Jahanpeyma, F. and Azam, K. (2005) Formaldehyde Exposure in Some Educational Hospitals of Tehran. Industrial Health, 43, 703-707.

[15] Orsière, T., Sari-Minodier, I., Iarmarcovai, G. and Botta, A. (2006) Genotoxic Risk Assessment of Pathology and Anatomy Laboratory Workers Exposed to Formaldehyde by the Use of Personal Air Sampling and Analysis of DNA Damage in Peripheral Lymphocytes. Mutation Research/Genetic Toxicology and Environmental Mutagenesis, 605, 30-41. https://doi.org/10.1016/j.mrgentox.2006.01.006

[16] Doty, R.L., Cometto-Muniz, J.E., Jalowayski, A.A., Dalton, P., Kendel-Reed, M. and Hodqson, M. (2004) Assessment of Upper Respiratory Tract and Ocular Irritative Effects of Volatile Chemicals in Humans. Critical Reviews in Toxicology, 34, 85-142. https://doi.org/10.1080/10408440490269586

[17] Agency for Toxic Substances and Disease Registry (ATSDR) (1987) Toxicological Profile for Formaldehyde (Draft). Public Health Services, United States Department of Health and Human Services, Atlanta, GA.

[18] IARC Working Group on the Evaluation of Carcinogenic Risk to Humans (2006) Formaldehyde, 2-Butoxyethanol and 0-Tert-Butoxypropan-2-Ol. International Agency for Research on Cancer, Lyon, France.

[19] NIOSH Bulletin (1981) Current Intelligence Bulletin 34. U.S. Department of Health and Human Services, Public Health Service, Center for Disease Control.

[20] Walrath, J. and Fraumeni, J.F. (1984) Cancer and Other Causes of Death among Embalmers. Cancer Research, 44, 4638-4641.

[21] Harrington, J.M. and Shannon, H. (1975) Mortality Study of Pathologists and Medical Laboratory Technicians. British Medical Journal, 4, 329-332.

https://doi.org/10.1136/bmj.4.5992.329

[22] Stellman, S.D., Demers, P.A., Colin, D. and Boffetta, P. (1988) Cancer Mortality and Wood Dust Exposure among Participants in the American Cancer Society Cancer Prevention Study-II (CPS-II). American Journal of Industrial Medicine, 34, 229-237.

https://doi.org/10.1002/(SICI)1097-0274(199809)34:3<229::AID-AJIM4>3.0.CO;2-Q

[23] Beane-Freeman, L.E., Blair, A., Lubin, J.H., Stewart, P.A., Hayes, R.B., Hoover, R.N., et al. (2009) Mortality from Lymphohematopoietic Malignancies among Workers in Formaldehyde Industries: The National Cancer Institute Cohort. Journal of the National Cancer Institute, 101, 751-761. https://doi.org/10.1093/jnci/djp096

[24] Gardner, M.J., Pannett, B., Winter, P.D. and Cruddes, A.M. (1993) A Cohort Study of Workers Exposed to Formaldehyde in the British Chemical Industry: An Update. British Journal of Industrial Medicine, 50, 827-834. https://doi.org/10.1136/oem.50.9.827

[25] Coggon, D., Harris, E.C., Poole, J. and Palmer, K.T. (2003) Extended Follow-Up of a 
Cohort of British Chemical Workers Exposed to Formaldehyde. Journal of the National Cancer Institute, 95, 1608-1615. https://doi.org/10.1093/jnci/djg046

[26] United States Occupational Safety and Health Administration (1993) Occupational Safety and Health Standards, Toxic and Hazardous Substances, Standard Number 1910-1048 (c). United States Department of Labor, Washington DC.

[27] Malaysia Occupational Safety and Health Act and Regulations Act 514 (1994) Use and Standards of Exposure of Chemicals Hazardous to Health Regulations 2000. MDC Publishers Sdn Bhd, Kuala Lumpur, Malaysia.

[28] Wilhelmsson, B. and Holmström, M (1992) Possible Mechanisms of Formaldehyde-Induced Discomfort in the Upper Airways. Scandinavian Journal of Work, Environment \& Health, 18, 403-407. https://doi.org/10.5271/sjweh.1556

[29] Emory University (2012) Formaldehyde Questionnaire. Environmental Health and Safety Office, Georgia.

[30] United States Occupational Safety and Health Administration (1993) Non-Mandatory Medical Disease Questionnaire, Occupational Safety and Health Standards, Toxic and Hazardous Substances, Standard Number 1910.1048 App D. United States Department of Labor, Washington DC.

[31] Industry Code of Practice on Indoor Air (2010) Questionnaire for Building Occupants. Quality Ministry of Human Resources, Department of Occupational Safety and Health, Malaysia.

[32] United States Environmental Protection Agency (USEPA) (1989) Risk Assessment Guidance for Superfund Volume I: Human Health Evaluation Manual (Part A). Washington DC.

[33] United States Environmental Protection Agency (USEPA) (2009) Risk Assessment Guidance for Superfund Volume I: Human Health Evaluation Manual (Part F, Supplemental Guidance for Inhalation Risk Assessment). Washington DC.

[34] United States Environmental Protection Agency (USEPA) (2010) IRIS Toxicological Review of Formaldehyde (Inhalation) (External Review Draft 2010). Washington DC, EPA/635/R-10/002A.

[35] Liu, K.S., Huang, F.Y., Hayward, S.B., Wesolowski, J. and Sexton, K. (1991) Irritant Effects of Formaldehyde Exposure in Mobile Homes. Environmental Health Perspectives, 94, 91-94. https://doi.org/10.1289/ehp.94-1567965

[36] National Research Council (2011) Review of the Environmental Protection Agency's Draft IRIS Assessment of Formaldehyde. Reference Concentrations for Non-Cancer Effects and Unit Risks for Cancers. The National Academies Press, Washington DC.

[37] United States Environmental Protection Agency (USEPA) (1986) Guidelines for Carcinogen Risk Assessment, Federal Regulation. United States Environmental Protection Agency, Washington DC.

[38] World Health Organization (WHO) (2000) World Health Organization Guidelines for Air Quality. Geneva, Switzerland.

[39] Woodruff, T.J., Caldwell, J., Cogliano, V.J. and Axelrad, D.A. (1990) Estimating Cancer Risk from Outdoor Concentrations of Hazardous Air Pollutants in 1990. Environmental Research, 82, 194-206. https://doi.org/10.1006/enrs.1999.4021

[40] Morello-Frosch, R.A., Woodruff, T.J., Axelrad, D.A. and Caldwell, J.C. (2005) Air Toxic and Health Risk in California: The Public Health Implications of Outdoor Concentrations. Risk Analysis, 20, 273-292. https://doi.org/10.1111/0272-4332.202026

[41] United States Environmental Protection Agency (USEPA) (2005) Guidelines for 
Carcinogen Risk Assessment, Risk Assessment Forum. United States Environmental Protection Agency, Washington DC.

[42] Industry Code of Practice on Indoor Air Quality (2010) Table I: List of Indoor Air Contaminants and the Maximum Limits. Ministry of Human Resources, Department of Occupational Safety and Health, Malaysia.

[43] Salthammer, T., Mentese, S. and Marutzky, R. (2010) Formaldehyde in the Indoor Environment. Chemical Reviews, 110, 2536-2572. https://doi.org/10.1021/cr800399g

[44] Du, Z.-J., Mo, J.-H., Zhang, Y.-P. and Xu, Q.-J. (2014) Benzene, Toluene and Xylenes in Newly Renovated Homes and Associated Health Risk in Guangzhou, China. Building Environment, 72, 75-81. https://doi.org/10.1016/j.buildenv.2013.10.013

[45] Ladeira, C., Viegas, S., Carolino, E., Prsista, J., Gomes, M.C. and Brito, M. (2011) Genotoxicity Biomarker in Occupational Exposure to Formaldehyde-The Case of Histopathology Laboratories. Mutation Research/Genetic Toxicology and Environmental Mutagenesis, 721, 15-20. https://doi.org/10.1016/j.mrgentox.2010.11.015

[46] Ahmed, H.O. (2011) Preliminary Study: Formaldehyde Exposure in Laboratories of Sharjah University in UAE. Indian Journal of Occupational \& Environmental Medicine, 15, 33-37. https://doi.org/10.4103/0019-5278.82997

[47] Xu, W. and Stewart, E.J. (2016) A Comparison of Engineering Controls for Formaldehyde Exposure during Grossing Activities in Health Care Anatomic Pathology Laboratories. Journal of Occupational and Environmental Hygiene, 13, 529-537. https://doi.org/10.1080/15459624.2016.1149182

[48] Ogawa, M., Kabe, I., Terauchi, Y. and Tanaka, S. (2018) A Strategy for the Reduction of Formaldehyde Concentration in a Hospital Pathology Laboratory. Journal of Occupational Health, 61, 135-142. https://doi.org/10.1002/1348-9585.12018

[49] Roland, O.W., Douglas, K.E. and Akaranta, O. (2019) Comparative Assessment of Formaldehyde Concentrations in Public and Private Mortuaries in Rivers State, Nigeria. Journal of Scientific Research \& Reports, 23, 1-11. https://doi.org/10.9734/jsrr/2019/v23i230115

[50] Azari, M.R., Asadi, P., Jafari, M.J., Soori, H. and Hosseini, V. (2012) Occupational Exposure of a Medical School Staff to Formaldehyde in Tehran. Tanaffos, 11, 36-41.

[51] Amoore, J.E. and Hautala, E. (1983) Odor as an Ald to Chemical Safety: Odor Thresholds Compared with Threshold Limit Values and Volatilities for 214 Industrial Chemicals in Air and Water Dilution. Journal of Applied Toxicology, 3, 272-290. https://doi.org/10.1002/jat.2550030603

[52] Harvey, C., Linda, D.D., Boffetta, P., Gallagher, A.E., Crawford, L., Lees, P.J.L., et al. (2015) Formaldehyde Exposure and Mortality Risks from Acute Myeloid Leukemia and Other Lymphohematopoietic Malignancies in the Us National Cancer Institute Cohort Study of Workers in Formaldehyde Industries. Journal of Occupational and Environmental Medicine, 57, 785-794.

https://doi.org/10.1097/JOM.0000000000000466 